\title{
Lactotroph Adenoma
}

National Cancer Institute

\section{Source}

National Cancer Institute. Lactotroph Adenoma. NCI Thesaurus. Code C3342.

An adenoma of the anterior lobe of the pituitary gland that produces prolactin. It is the most common type of pituitary gland adenomas and it is associated with hyperprolactinemia. Clinical manifestations include amenorrhea, galactorrhea, impotence, headache, and visual disturbances. 